\title{
Centralized Library Purchasing and Technical Processing for Six Colleges in Alabama and Mississippi; A Report
}

\begin{abstract}
The United Board for College Development proposes centralized library purchasing and processing of materials to increase the educational potential of Miles, Oakwood, Stillman, Tuscaloosa, and Tougaloo Colleges, and Tuskegee Institute as quickly as possible. The colleges are similar enough in course offerings, acquisitions practices, and cataloging policies to make centralization feasible. Plans for development include funding a center and the acquisition of additional materials, and encouraging other similar libraries to take advantage of the center's services.
\end{abstract}

$\mathrm{T}$ HE UNITED BOARD for College Development has initiated a special effort to increase the quantity and quality of educational materials at Miles, Oakwood, Stillman, Tougaloo, and Tuscaloosa Colleges, and at Tuskegee Institute. The project began formally after the administrative officers and the librarians of the six colleges, and two consultants, Warren J. Haas and Maurice F. Tauber, met with Board Director Charles C. Turner and concluded that the needs for materials are greater than the abilities of the libraries to supply them. The group decided that a feasibility study should be conducted to determine the best method of solving the problem. The Board succeeded in obtaining funds and chose the present authors as Principal Investigator and Associate Investigator, respectively.

The two investigators attempted to: (1) analyze the current selection and processing procedures in the six libraries

Mrs. Phinazee is Professor and Mr. Jordan is Assistant Professor of Library Service in Atlanta University. by identifying and describing relevant characteristics of the libraries and of their communities; (2) develop criteria for determining the adequacy of processing services, cost, status of cataloging, efficiency of operations, etc.; (3) study plans for future processing procedures that included estimates of the volume of material to be processed during the next three years, plans for expanding staff and facilities, and plans for improving conditions; and (4) identify solutions to the problems of fulfilling the processing requirements by evaluating present and future needs and proposing a plan that will provide adequate personnel, facilities, quarters, and an efficient system of processing operations, with cost estimates included.

After searching relevant literature, the investigators met with the librarians on two occasions; the college presidents, or their representatives, attended one of the meetings. Two questionnaires were distributed and analyzed. Each library was visited and the library personnel was interviewed.

Enrollment in these coeducational, 
undergraduate, liberal arts colleges ranges from 610 to 2,856 , with faculties varying in size from 43 to 295 . Tuskegee Institute offers some professional and technical graduate courses, but all six schools list similar courses in 27 subject areas. Library holdings in 1968 were reported as being between 28,422 and 135,000 volumes. Expenditures for library materials in 1967-68 ranged from $\$ 10,756$ to $\$ 79,000$. Unusually large proportions of gifts are received by these libraries. There are nineteen different kinds of special collections, all supervised by the main library staff.

The study revealed that all of the libraries need more funds than are now available to them in order to purchase the quantity of materials required. Their full-time nonprofessional and professional staffs would have to be increased substantially, and their facilities would have to be enlarged or rearranged to process materials more efficiently and cheaply.

A single center for the selection, ordering, cataloging, and processing of at least 90,000 volumes annually has been recommended for these six libraries for the following reasons: (1) there appeared to be a great deal of duplication of effort, with a negligible amount of unique technical processing being done in the libraries; (2) no significant differences in practices were found; (3) a center would cost less to operate than it would cost to expand facilities in the individual libraries and titles could be processed more cheaply; (4) professional personnel which is now involved in technical services would be free to contribute more toward the improvement of service by being released to plan, make policies, provide more guidance in the use of libraries, and actually get involved in the substantive aspect of the academic program. The center would employ a larger proportion of full-time nonprofessional workers-reducing the amount of time needed for supervision and, hopefully, increasing the quality of work.

The presidents and librarians have accepted this proposal. The librarians have agreed to standardize their practices and to accept the Library of Congress Classification system. Funds for the establishment of the center and for the purchase of materials are being sought.

Membership in the center by other similar libraries is being encouraged. Groups of librarians in Texas and South Carolina have expressed a desire to engage the services of the center. 